\title{
Validation of the Arabic Version of General Medication Adherence Scale (GMAS) in Sudanese Patients with Diabetes Mellitus
}

\author{
Mansour Adam Mahmoud (D) \\ Md Ashraful Islam ${ }^{2}$ \\ Malaz Ahmed (D) ${ }^{3}$ \\ Randa Bashir ${ }^{3}$ \\ Romisa Ibrahim ${ }^{3}$ \\ Shahd Al-Nemiri ${ }^{3}$ \\ Ethar Babiker ${ }^{3}$ \\ Neven Mutasim ${ }^{3}$ \\ Sultan Othman Alolayan' \\ Sultan Al Thagfan' \\ Samrein BM Ahmed ${ }^{4}$ \\ Ibrahim Sales $\mathbb{D}^{5}$ \\ Mohamed Azmi Hassali, ${ }^{6, \dagger}$ \\ Yaser Alahmadi ${ }^{\prime}{ }^{\prime}$ \\ Mirghani A Yousif ${ }^{3}$ \\ 'Department of Clinical \& Hospital \\ Pharmacy, College of Pharmacy, Taibah \\ University, Al-Madinah Al-Munawarah, \\ Saudi Arabia; ${ }^{2}$ Department of Pharmacy \\ Practice, College of Clinical Pharmacy, \\ Imam Abdulrahman Bin Faisal University, \\ Dammam, Saudi Arabia; ${ }^{3}$ Department of \\ Clinical Pharmacy \& Pharmacy Practice, \\ Faculty of Pharmacy, University of Gezira, \\ Wad Madani, Sudan; ${ }^{4}$ College of \\ Medicine, University of Sharjah, Sharjah, \\ United Arab Emirates; ${ }^{5}$ Department of \\ Clinical Pharmacy, College of Pharmacy, \\ King Saud University, Riyadh, Saudi \\ Arabia; ${ }^{6}$ Discipline of Social and \\ Administrative Pharmacy, School of \\ Pharmaceutical Sciences, Universiti Sains \\ Malaysia, Penang, Malaysia \\ †Mohamed Azmi Hassali passed away on \\ July I6, 202I
}

Correspondence: Mansour Adam Mahmoud Department of Clinical and Hospital

Pharmacy, College of Pharmacy, Al-Madinah

Al-Munawarrah, Saudi Arabia

Email Mammm.99@gmail.com
Objective: The aim of this study was to validate the Arabic version of General Medication Adherence Scale (GMAS) in Sudanese patients with type 2 diabetes mellitus (T2DM).

Methods: A 3-month cross-sectional study was conducted among patients with T2DM at AlDaraja Health Center, located in Wad Medani, Sudan. A convenient sample of patients was selected, and the study sample size was calculated using the item response ratio. Factorial, known group, and construct validities were determined. Internal consistency and reliability were also determined.

Results: Responses were provided by 500 patients. The average medication adherence score was 30 (median 31). The normed fit index (NFI) was 0.950 , the comparative fit index (CFI) was 0.963 , the incremental fit index (IFI) was 0.963 , and the root-mean-square error of approximation (RMSEA) was 0.071. The results from these fit indices indicated a good model. Factorial, known group and construct validities were all established. A significant association was found between adherence score and age $(\mathrm{P}=0.03)$ since a larger proportion of older patients were found to have high adherence compared to patients in other age groups. The reliability $(\alpha)$ of the questionnaire was 0.834 .

Conclusion: The Arabic version of GMAS was validated in Sudanese patients with T2DM making it a suitable scale to be used in this population.

Keywords: medication adherence, patient compliance, medication persistence, chronic illness, Sudan

\section{Introduction}

Diabetes mellitus (DM) is a global pandemic and approximately 19.4 million people live with diabetes in Africa. ${ }^{1}$ According to the International Diabetes Federation (IDF), the prevalence of DM in adults in Sudan in 2020 was $17.9 \%{ }^{2}$ The prevalence of type 2 DM (T2DM) in the Northern part of Sudan was estimated to be $18.7 \%{ }^{3}$ Risk factors for the development of DM in North Sudan were age above 60 , obesity, and urban residence. ${ }^{3}$ It has been reported that the annual medical expenditures for Sudanese patients with DM were fourfold higher for people with DM than those without DM. ${ }^{4}$ In addition, patients with DM were more likely to experience foot ulcers and cardiovascular diseases compared to patients without DM. ${ }^{4}$ The direct costs of diabetes control in Sudan, including the cost of drugs and ambulatory care, were equivalent to USD 175 per year in $2010 .^{5}$

Many patients in Sudan face financial issues due to a high inflation rate and the country's poor economic condition. The governmental pharmaceutical expenditures as of 2010 were USD 1349 and per capita pharmaceutical expenditures were USD 34.45. ${ }^{6}$ The majority of patients in Sudan are uninsured and pay for their 
medications out-of-pocket; therefore, patient adherence is suboptimal due to the inability to consistently obtain their medications. ${ }^{7}$ Poor adherence to anti-diabetic medications was reported among adults in many previous studies. ${ }^{8-10}$ Lack of insurance coverage, unavailability of medicine, financial difficulties, brand-name medication substitution, and patients' negative perceptions that some medicines are not necessary are some factors that have led to patients' inability to buy their anti-diabetic medications. ${ }^{9}$ Medication-related factors, such as side effects and the use of herbal medicine, were also reported as factors contributing to non-adherence. ${ }^{8,9}$

Measurement of medication adherence can be direct or indirect. Examples of direct medication adherence method are directly observed therapy and measurement of drug concentration or its metabolite in the blood or urine. Pill counts, self-reported questionnaires, assessment of the patient's clinical outcome and rates of prescription fills are instances of direct medication adherence. Each of these methods has advantages and disadvantages. Several validated adherence questionnaires are widely used in the clinical setting. One of the most commonly used is the Morisky Medication Adherence Scale (MMAS). First, a 4-item questionnaire was developed to study medicationtaking behaviors leading to omission of drug and later additional 4 items addressing conditions surrounding adherence behavior were added to the original version to overcome some of its limitations; this updated scale was named the 8-item Morisky Medication Adherence Scale (MMAS-8). ${ }^{11}$ The Medication Adherence Report Scale-10 (MARS-10) is a 10-item self-report adherence scale. It measures both intentional and nonintentional nonadherence and is intended to report some of the weaknesses of self-report measures. ${ }^{12}$ Assessment of medication adherence among Patients with DM is important for the development of evidence-based policies aimed at the prevention and management of DM. Previous studies conducted to assess adherence among patients with DM in Sudan used questionnaires that were validated in western countries. ${ }^{8}$ The Arabic version of General Medication Adherence Scale (GMAS) was validated in Saudi patients with chronic diseases, and it has been proposed to validate the tool in specific patient population such as diabetes. Moreover, Sudanese Arabic dialects are different from those of Saudi Arabia. Therefore, the aim of the current study was to validate an Arabic version of the GMAS in Sudanese patients with type T2DM.

\section{Methods}

\section{Study Design and Setting}

A cross-sectional study was conducted for three months, ie, February - April 2019 at Al-Daraja Governmental Health Center. This is an outpatient facility in the Wad Medani area and averages between 3000 and 4000 patient visits per month. The health facility offers preventative and management services for a variety of chronic diseases, administers children's vaccinations, and provides specialized services for patients with T2DM.

\section{Participants and Eligibility Criteria}

The study included adult ( $\geq 18$ years), ambulatory patients with T2DM with or without comorbidities, who were previously diagnosed with the disease and prescribed pharmacotherapy for T2DM for at least six months. Patients with other categories of diabetes, pregnancy, and planned surgery were excluded from the study.

\section{Sampling and Sample Size Calculation}

A convenient sample was selected, and all the patients accessible at the time of data collection were asked to participate. The sample size was calculated using the item response theory, and utilized an item-subject ratio of 1:30 plus $20 \%$ drop-out rate. ${ }^{13-16}$ Therefore, we required a sample of 396 patients.

\section{Patient Recruitment and Data Collection}

Patients were recruited from an outpatients DM clinic. On clinic day, a random sample list of eligible patients was generated and approached. Patients were asked to read and sign a consent form. Patients who agreed to participate were asked to fill the GMAS questionnaire.

\section{Research Instrument}

The eleven-item GMAS was originally developed by Naqvi et al in the Urdu language for Pakistani patients. ${ }^{12}$ Subsequently, after a successful validation of the results, the scale was translated into the English language and was validated in both the Pakistani and Saudi populations. ${ }^{13,17}$ Arabic and Chinese versions of the scale have recently been validated in the Saudi and Chinese populations, respectively. ${ }^{18,19}$ The highest score that can be achieved is 33. Based upon the score, adherence levels are categorized as high, ${ }^{27-31}$ good, ${ }^{25-27}$ partial, ${ }^{15-24}$ low $^{9-14}$ and poor $(\leq 10)$. The adherence may also be categorized as adherent $(\geq 27)$ or non-adherent $(\leq 26) .{ }^{18}$ The scale was developed to assess adherence in the 
general population and is not limited to any particular disease state. This tool measures the unintentional and intentional non-adherence to medications, non-adherence to comorbidity and pill burden and cost-related non-adherence.

\section{Construct Validity}

Construct validity was established by conducting Confirmatory Factor Analysis (CFA) and a structure equation model. Fit indices are, namely, comparative fit index (CFI), goodness-of-fit index (GFI), adjusted goodness-of-fit index (AGFI), Tucker Lewis index (TLI), and root-meansquare error of approximation (RMSEA). Values of AGFI and CFI $\geq 0.9$, and for TLI and GFI $\geq 0.95$ were considered acceptable. Further, a significant chi-square value $(\mathrm{p}<0.05)$ and chi-square/df ratio $<5$ were also considered. We considered construct validity to be established if the majority of fit indices were in their acceptable ranges. ${ }^{20,21}$

\section{Known Group Validity}

Based on previous research, we hypothesized that a relationship between age and medication adherence exists among Sudanese patients with DM. ${ }^{22}$ This hypothesis was tested by cross tabulating the variables of both age and adherence categories. This technique evaluates the ability of the scale to discern among samples with known traits. ${ }^{16}$ The known group validity was established if the $\chi^{2}$ was significant, ie, $\mathrm{p}<0.05$. $^{23-26}$

\section{Internal Consistency}

The internal consistency of the tool was assessed through Cronbach's alpha $(\alpha)$ value. Item-to-total correlation (ITC) and intraclass correlation coefficient (ICC) were also calculated. ICC was also expressed in 95\% confidence interval (CI) ranges. The inter-item correlation matrix was assessed to evaluate the correlations among scale items. An $\alpha$ value above 0.5 was considered satisfactory. ${ }^{23,24}$ ITC and ICC values $>0.2$ were considered acceptable. ${ }^{28-30}$

\section{Ethics Approval and Patient Consent}

Patient permission was obtained before conducting the survey. A written informed consent form was provided to all patients at the time of enrollment. Those who signed the consent form were included in the study and provided with the survey. Participation was voluntary. The study was approved by the Gezira State Ministry of Health (No. A/K/T/44) and ethical committee of the healthcare facility and the IRB Committee of Wad Medani College of Medical Sciences and Technology.
The study was conducted in accordance with the Declaration of Helsinki.

\section{Results}

A total of 500 patients responded to the study. Most patients $(\mathrm{N}=219,43.8 \%)$ were in the age range of between 59 and 78 years. The majority of patients were female $(\mathrm{N}=355$, $71 \%$ ). Most patients were married ( $\mathrm{N}=465,93 \%)$, homemakers $(\mathrm{N}=283,56.6 \%)$, and did not earn any family income $(\mathrm{N}=313,62.6 \%)$. More than a third had primary education ( $\mathrm{N}=176,35.2 \%)$, and over half of the patients had comorbidities $(\mathrm{N}=266,53.2 \%)$. A third $(\mathrm{N}=165,62 \%)$ of patients with comorbidities had hypertension, and some had a combination of hypertension and hyperlipidemia $(\mathrm{N}=$ $56,21.2 \%)$. A minority of patients $(\mathrm{N}=45,16.9 \%)$ had pulmonary and musculoskeletal diseases. Most patients $(\mathrm{N}=$ $367,73.4 \%$ ) had a HbAlc (\%) of $\leq 7 \%$. The demographic information of the participants is provided in Table 1.

The average medication adherence score was 30 (mean 30.06, SD 3.66, median 31, IQR 4). The minimum score reported was 11, and the maximum score was 33 .

\section{Construct Validity}

Results from CFA reported that the values for the fit indices were as follows: $\mathrm{CFI}=0.936, \mathrm{GFI}=0.948, \mathrm{AGFI}=0.915, \mathrm{TLI}$ $=0.913$, and RMSEA $=0.073$. The values for AGFI and CFI were $\geq 0.9$, and for TLI slightly less than 0.95 , while it was roughly equal to 0.95 for GFI. The value for RMSEA was $<0.08$ and also indicated an acceptable model fit. Furthermore, the chi-square value was significant, ie, $\mathrm{p}<0.05$ and chisquare/df ratio was $<5$. Therefore, all values except for TLI were in acceptable range. These results established the construct validity of the scale (Figure 1). The individual item factor loadings are listed in Table 2.

\section{Known Group Validity}

There was a significant association (Fisher exact $\chi^{2}=12.850$, $\mathrm{p}=0.033$ ) between the age and adherence variables since a larger proportion of older patients were found to have high adherence compared to patients in other age groups (Table 3 ).

\section{Internal Consistency}

The reliability $(\alpha)$ of the questionnaire was 0.834 which was acceptable. The minimum value for ITC was 0.296, ie, $>0.2$ which was also acceptable (Table 2). Item correlation matrix revealed that all items were positively correlated with the minimum correlation coefficient value of 
Table I Participant Demographics $(N=500)$

\begin{tabular}{|c|c|}
\hline Patient Information & $\mathbf{N}(\%)$ \\
\hline \multicolumn{2}{|l|}{ Age group } \\
\hline Between 18 and 38 years & $25(5)$ \\
\hline Between 39 and 58 years & $214(42.8)$ \\
\hline 59 and above & $26 \mid(52.2)$ \\
\hline \multicolumn{2}{|l|}{ Gender } \\
\hline Male & 145 (29) \\
\hline Female & $355(7 I)$ \\
\hline \multicolumn{2}{|l|}{ Marital Status } \\
\hline Married & $465(93)$ \\
\hline Single & $35(7)$ \\
\hline \multicolumn{2}{|l|}{ Educational level } \\
\hline No formal education & $126(25.2)$ \\
\hline Primary education & $176(35.2)$ \\
\hline Intermediate education & $57(11.4)$ \\
\hline Secondary education & $92(18.4)$ \\
\hline College graduate & $49(9.8)$ \\
\hline \multicolumn{2}{|l|}{ Employment } \\
\hline Employed & 145 (29) \\
\hline Un-employed & $24(4.8)$ \\
\hline Household & $283(56.6)$ \\
\hline Retired & $48(9.6)$ \\
\hline \multicolumn{2}{|l|}{ Monthly family income } \\
\hline No income & $313(62.6)$ \\
\hline Less than 5000 SDG ie, USD $<110.38$ & $123(24.6)$ \\
\hline Between 5000-10,000 SDG ie, USD II0.30-220.75 & $32(6.4)$ \\
\hline Between $10,000-\mid 5,000$ SDG ie, USD 220.75-33|.13 & $8(1.6)$ \\
\hline More than 15,000 SDG ie, USD $>331.13$ & $24(4.8)$ \\
\hline \multicolumn{2}{|l|}{ Comorbidities } \\
\hline No comorbidity & $234(46.8)$ \\
\hline Comorbidity present & $266(53.2)$ \\
\hline \multicolumn{2}{|l|}{ HbAlc } \\
\hline$\leq 7 \%$ & $367(73.4)$ \\
\hline$>7 \%$ & $133(26.6)$ \\
\hline \multicolumn{2}{|l|}{ Adherence to medications } \\
\hline High adherence & $345(69)$ \\
\hline Good adherence & $94(18.8)$ \\
\hline Partial adherence & $57(11.4)$ \\
\hline Low adherence & $4(0.8)$ \\
\hline
\end{tabular}

Note: I USD equals SDG 45.3.

Abbreviations: SDG, Sudanese pound; USD, United States Dollar.

0.127 and maximum value of 0.614 . ICC was 0.834 (0.812-0.855 for $95 \% \mathrm{CI})$.

\section{Discussion}

This study reported patients' adherence to anti-diabetic medications among adult Sudanese patients attending an outpatient clinic. One quarter of the patients had $\mathrm{HbAlc}$ $\geq 7 \%$. Patient adherence was measured using the Arabic version of GMAS, and it was found that $69 \%$ had high adherence, while approximately $11 \%$ of the patients had partial adherence. In contrast, one study reported that $15 \%$ of patients had high adherence and $44.6 \%$ had medium adherence to anti-diabetic medications. Furthermore, Mikhael et al reported that $77.5 \%$ of patients had moderate and high adherence to anti-diabetic medications in the Iraqi Anti-Diabetic Medication Adherence Scale conducted in the Arabic language. ${ }^{31}$

The Arabic version of GMAS was validated in Sudanese patients with diabetes. The Arabic version was previously validated in Saudi patients with chronic diseases. ${ }^{16}$ In the current study, the known group validity was evaluated by testing the hypothesis that age relates to medication adherence. Our study results showed that older patients had significantly higher adherence compared to other age groups. This finding was comparable to previously published results. ${ }^{2,32,33}$ Likewise, Sudanese patients with diabetes above 60 years old have consistently reported higher adherence to their diabetes medication than younger patients. ${ }^{8,9}$ This could be because they have had diabetes for a longer period of time and may have started to experience more complications than their younger counterparts. Furthermore, the sample size in our study was larger than several recent studies conducted to measure adherence among patients with diabetes. . $^{8,9,22,28}$

The construct validity of the Arabic version of GMAS was evaluated by associating the adherence categories with the $\mathrm{HbA} 1 \mathrm{c}(\%)$. Evidence has shown that patients adherence to their anti-diabetic medications is associated with diabetes control. ${ }^{34}$ In the current study, patients with HbA1c values of $\leq 7 \%$ reported high levels of adherence; however, patients with $\mathrm{HbA} 1 \mathrm{c}$ values greater than $7 \%$ more frequently reported having good, partial, and low levels of adherence. Michael et al reported that only $33 \%$ of patients with controlled diabetes had moderate and high levels of adherence. ${ }^{31}$ Furthermore, these results provided sufficient evidence to establish construct validity of the tool. In addition, the reliability of the Arabic version of the scale, ie, 0.834, in the current study was quite high. This is similar to the reliability reported in the Arabic version validated in Saudi Arabia. ${ }^{18}$ Moreover, it was higher than the values reported in the studies validating the 8-item Morisky's Medication Adherence Scale (MMAS-8), ie, 0.7, and the English version of GMAS in the Saudi population, ie, $0.74 .^{17}$ 


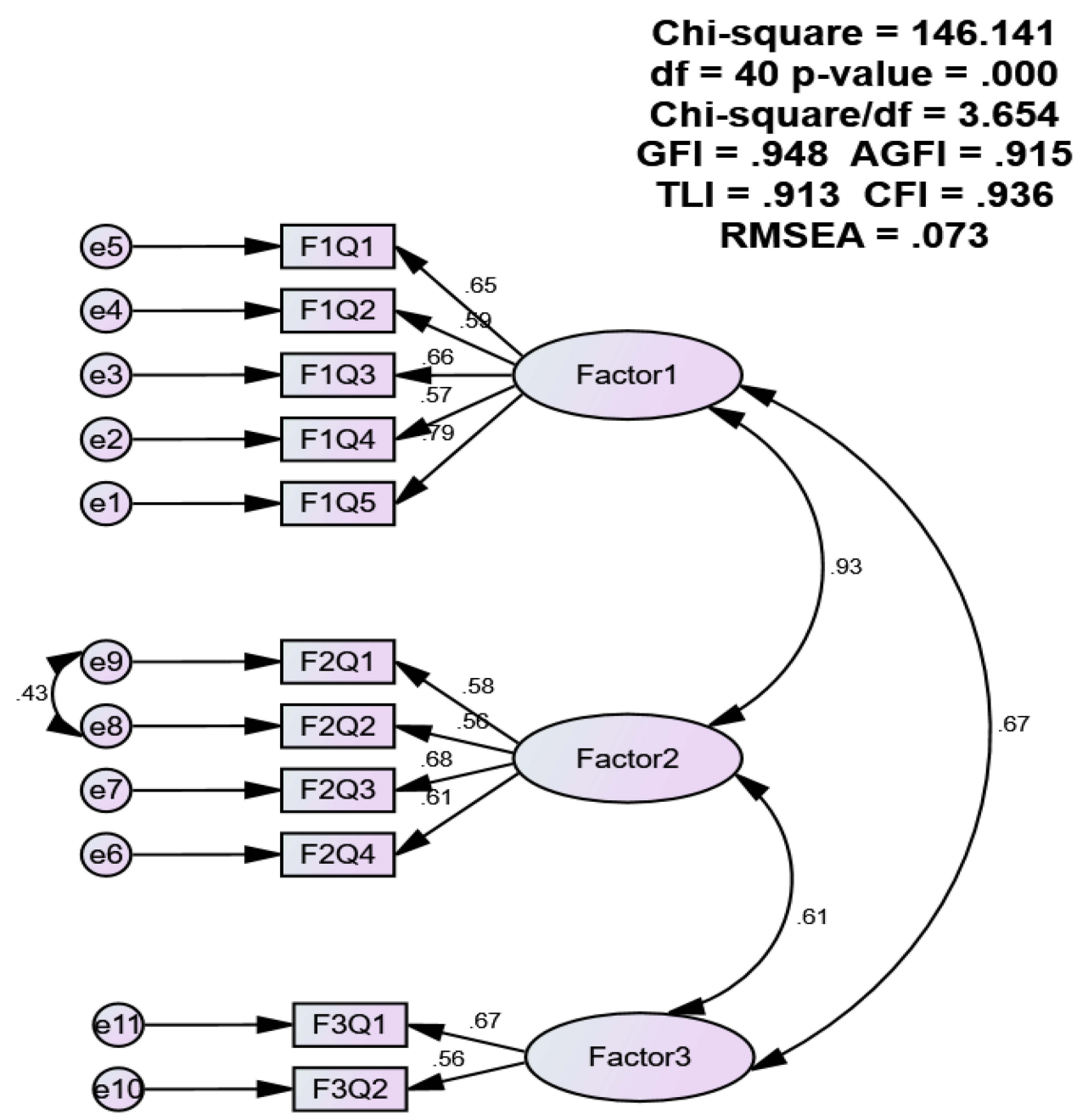

Figure I Structure equation model.

Published studies to assess patients' adherence in Sudan have been plagued with several limitations. The majority of the studies have either not used well-validated

Table 2 GMAS Item Characteristics

\begin{tabular}{|l|c|c|c|}
\hline Items & $\begin{array}{c}\text { Highest Factor } \\
\text { Loadings }\end{array}$ & ITC & $\begin{array}{c}\text { Cronbach }(\boldsymbol{\alpha}) \text { If Item } \\
\text { Deleted }\end{array}$ \\
\hline 1 & 0.729 & 0.551 & 0.817 \\
2 & 0.768 & 0.500 & 0.823 \\
3 & 0.644 & 0.570 & 0.816 \\
4 & 0.607 & 0.500 & 0.821 \\
5 & 0.737 & 0.670 & 0.806 \\
6 & 0.849 & 0.558 & 0.819 \\
7 & 0.810 & 0.538 & 0.818 \\
8 & 0.576 & 0.626 & 0.810 \\
9 & 0.535 & 0.557 & 0.816 \\
10 & 0.790 & 0.376 & 0.830 \\
11 & 0.815 & 0.296 & 0.846 \\
\hline
\end{tabular}

questionnaires or did not conduct psychometric property analysis of the previously validated questionnaires. ${ }^{8,9}$ The GMAS was formulated in a developing country with similar financial issues faced by Sudanese patients, thus making it more suitable to be used in Sudan. This study has a few limitations worth mentioning. The test-retest reliability was not conducted, and the concurrent validity of the scale was not established. These two facets of validation would have added to the scale's strength. Nevertheless, the validities that were established coupled with satisfactory reliability are indicative of the scale's ability to measure medication adherence in this patient population.

\section{Conclusion}

The Arabic version of GMAS was found to be valid in Sudanese patients with T2DM. The availability of a culturally and social-economically appropriate medication adherence scale for public use should assist 
Table 3 Cross Tabulation Between Age (Years) and Adherence Categories Based on GMAS Score

\begin{tabular}{|c|c|c|c|c|c|}
\hline \multirow[t]{2}{*}{ Age (Years) } & \multirow[t]{2}{*}{ Counts } & \multicolumn{4}{|c|}{ Adherence Categories* } \\
\hline & & High Adherence & Good Adherence & Partial Adherence & Low Adherence \\
\hline \multirow[t]{4}{*}{ 18-38 } & Count & 13 & 5 & 7 & 0 \\
\hline & $\%$ within age & $52 \%$ & $20 \%$ & $28 \%$ & $0 \%$ \\
\hline & $\%$ within adherence categories & $3.8 \%$ & $5.3 \%$ & $12.3 \%$ & $0 \%$ \\
\hline & $\%$ of Total & $2.6 \%$ & $1 \%$ & $1.4 \%$ & $0 \%$ \\
\hline \multirow[t]{4}{*}{$39-58$} & Count & 142 & 44 & 24 & 4 \\
\hline & $\%$ within age & $66.4 \%$ & $20.6 \%$ & $11.2 \%$ & $1.9 \%$ \\
\hline & $\%$ within adherence categories & $41.2 \%$ & $46.8 \%$ & $42.1 \%$ & $100 \%$ \\
\hline & $\%$ of Total & $28.4 \%$ & $8.8 \%$ & $4.8 \%$ & $0.8 \%$ \\
\hline \multirow[t]{4}{*}{59 and above } & Count & 190 & 45 & 26 & 0 \\
\hline & $\%$ within age & $72.8 \%$ & $17.2 \%$ & $10 \%$ & $0 \%$ \\
\hline & $\%$ within adherence categories & $55.1 \%$ & $47.9 \%$ & $45.6 \%$ & $0 \%$ \\
\hline & $\%$ of Total & $38 \%$ & $9.0 \%$ & $5.2 \%$ & $0 \%$ \\
\hline
\end{tabular}

Note: *Fisher exact test.

clinicians in their assessment of patients with chronic diseases such as DM. This version of GMAS is recommended to be validated in Sudanese patients with other chronic diseases.

\section{Author Contributions}

All authors contributed to data analysis, drafting or revising the article, gave final approval for the version to be published, agreed to the submitted journal, and agreed to be accountable for all aspects of the work.

\section{Disclosure}

The authors report no conflicts of interest in this work and declare that the research was conducted in the absence of any commercial or financial relationships that could be construed as a potential conflict of interest.

\section{References}

1. Williams R. IDF Diabetes Atlas. 9th ed. Brussels, Belgium; 2019. Available from: https://www.diabetesatlas.org. Accessed March 30, 2021.

2. International Diabetes Federation. IDF MENA members; Sudan; 2020. Available from: https://idf.org/our-network/regions-members/middleeast-and-north-africa/members/47-sudan.html. Accessed October 4, 2021.

3. Eltom MA, Babiker Mohamed AH, Elrayah-Eliadarous H. et al. Increasing prevalence of type 2 diabetes mellitus and impact of ethnicity in North Sudan. Diabetes Res Clin Pract. 2018;136:93-99. doi:10.1016/j.diabres.2017.11.034

4. Elrayah-Eliadarous HA, Östenson C-G, Eltom M, et al. Economic and social impact of diabetes mellitus in a low-income country: a case-control study in Sudan. J Diabetes. 2017;9(12):1082-1090.

5. Elrayah-Eliadarous H, Yassin K, Eltom M, et al. Direct costs for care and glycaemic control in patients with type 2 diabetes in Sudan. Exp Clin Endocrinol Diabetes. 2010;118(4):220-225.
6. World Health Organization. Sudan country profile; 2010.

7. Khogali SS, Ali WA, Mohamed SY, et al. Knowledge, attitude and practice of Sudanese individuals with type 2 diabetes about medication used in treatment of diabetes, hypertension and dyslipidaemia: a matter of debate or matter of concern?. J Public Health Emerg. 2018;2:23. doi:10.21037/jphe.2018.08.02

8. Badi S, Abdalla A, Altayeb L, et al. Adherence to antidiabetic medications among Sudanese individuals with type 2 diabetes mellitus: a cross-sectional survey. $J$ Patient Exp. 2020;7 (2):163-168.

9. EI-Hadiyah TM, Madani AM, Abdelrahim HM, Yousif AK. Factors affecting medication non adherence in type 2 Sudanese diabetic patients. Pharmacol Pharm. 2016;07(04):141-146. doi:10.4236/ pp.2016.74018

10. Elrayah H, Eltom M, Bedri A, et al. Economic burden on families of childhood type 1 diabetes in Urban Sudan. Diabetes Res Clin Pract. 2005;70(2):159-165. doi:10.1016/j.diabres.2005.03.034

11. AlGhurair SA, Hughes CA, Simpson SH, Guirguis LM. A systematic review of patient self-reported barriers of adherence to antihypertensive medications using the world health organization multidimensional adherence model. $J$ Clin Hypertens. 2012;14(12):877-886. PMID: 23205755. doi:10.1111/j.17517176.2012.00699.x.

12. Chan AHY, Horne R, Hankins M, Chisari C. The medication adherence report scale: a measurement tool for eliciting patients' reports of nonadherence. $\mathrm{Br} J$ Clin Pharmacol. 2020;86 (7):1281-1288. PMID: 31823381; PMCID: PMC7319010. doi:10.1111/bcp. 14193 .

13. Naqvi AA, Hassali MA, Rizvi M, et al. Development and validation of a novel General Medication Adherence Scale (GMAS) for chronic illness patients in Pakistan. Front Pharmacol. 2018;9(OCT). doi:10.3389/fphar.2018.01124

14. Naqvi AA, Hassali MA, Jahangir A, et al. Translation and validation of the English version of the General Medication Adherence Scale (GMAS) in patients with chronic illnesses. J Drug Assess. 2019;8 (1):36-42. doi:10.1080/21556660.2019.1579729

15. Osborne JW, Costello AB. Sample size and subject to item ratio in principal components analysis. Pract Assess Res Eval. 2004;9 (11): 11 .

16. Williams B, Onsman A, Brown T. Exploratory factor analysis: a five-step guide for novices. J Emerg Primary Health Care. 2010;8 (3):1-13. 
17. Naqvi AA, AlShayban DM, Ghori SA, et al. Validation of the general medication adherence scale in Saudi patients with chronic diseases. Front Pharmacol. 2019;10. doi:10.3389/fphar.2019.00633

18. Naqvi AA, Mahmoud MA, AlShayban DM, et al. Translation and validation of the Arabic version of the General Medication Adherence Scale (GMAS) in Saudi patients with chronic illnesses. Saudi Pharm J. 2020;28(9):1055-1061.

19. Wang Y, Wang X, Wang X, et al. Translation and validation of the Chinese version of the General Medication Adherence Scale (GMAS) in patients with chronic illness. Curr Med Res Opin. 2021;1. doi:10.1080/03007995.2021.1965974

20. Piedmont RL. Inter-item correlations. In: Encyclopedia of Quality of Life and Well-Being Research. Netherlands: Springer; 2014:3303-3304

21. Cornell University, Cornell Statistical Consultancy Unit, Stephen Parry. Principles and practice of structural equation modeling. Rex B. Kline; 2005.

22. Mirghani HO. An evaluation of adherence to anti-diabetic medications among type 2 diabetic patients in a Sudanese outpatient clinic. Pan Afr Med J. 2019;34. doi:10.11604/pamj.2019.34.34.15161

23. Cohen J. Statistical Power Analysis for the Behavioral Sciences Statistical Power Analysis for the Behavioral Sciences. 2nd ed. New York: Lawrence Erlbaum Associates; 2013.

24. DeVellis RF. Scale Development: Theory and Applications. 4th ed. Sage Publishing; 2016.

25. Iuga AO, McGuire MJ. Adherence and health care costs. Risk Manag Healthc Policy. 2014;7:35-44.
26. Kurlander JE, Kerr EA, Krein S, et al. Cost-related nonadherence to medications among patients with diabetes and chronic pain: factors beyond finances. Diabetes Care. 2009;32(12):2143-2148.

27. Cronbach LJ, Meehl PE. Construct validity in psychological tests. Psychol Bull. 1955;52(4):281-302. doi:10.1037/h0040957

28. Bowling A. Research Methods in Health: Investigating Health and Health Services. 4th ed. Buckingham: Open University Press; 2014.

29. Lahey MA, Downey RG, Saal FE. Intraclass correlations: there's more there than meets the eye. Psychol Bull. 1983;93(3):586-595. doi:10.1037/0033-2909.93.3.586

30. Sushil S, Verma N. Questionnaire validation made easy. Eur J Sci Res. 2010;46(2):172-178.

31. Mikhael EM, Hussain SA, Shawky N, et al. Validity and reliability of anti-diabetic medication adherence scale among patients with diabetes in Baghdad, Iraq: a pilot study. BMJ Open Diabetes Res Care. 2019;7:e000658. doi:10.1136/bmjdrc-2019-000658

32. Aloudah NM, Scott NW, Aljadhey HS, et al. Medication adherence among patients with type 2 diabetes: a mixed methods study. PLoS One. 2018;13(12):e0207583. doi:10.1371/journal.pone.0207583

33. Elsous A, Radwan M, Al-Sharif H, Mustafa AA. Medications adherence and associated factors among patients with type 2 diabetes mellitus in the Gaza Strip, Palestine. Front Endocrinol. 2017;8 (JUN). doi:10.3389/fendo.2017.00100

34. Krapek K, King K, Warren SS, et al. Medication adherence and associated hemoglobin A 1c in type 2 diabetes. Ann Pharmacother. 2004;38(9):1357-1362. doi:10.1345/aph.1D612
Risk Management and Healthcare Policy

\section{Publish your work in this journal}

Risk Management and Healthcare Policy is an international, peerreviewed, open access journal focusing on all aspects of public health, policy, and preventative measures to promote good health and improve morbidity and mortality in the population. The journal welcomes submitted papers covering original research, basic science, clinical \& epidemiological studies, reviews and evaluations, guidelines, expert opinion and commentary, case reports and extended reports. The manuscript management system is completely online and includes a very quick and fair peer-review system, which is all easy to use. Visit http://www.dovepress.com/testimonials.php to read real quotes from published authors. 